\title{
Varicocele and the outcomes of microdissection testicular sperm extraction in non-obstructive azoospermia: a case-control study
}

\begin{abstract}
Purpose: The effect of varicocele and varicocele repair on microdissection testicular sperm extraction (micro TESE) outcomes is controversial.

Methods: A retrospective case-control study of non-obstructive azoospermia patients undergoing micro TESE at a tertiary-care hospital.

Results: Varicocele was less likely to be present in successful micro TESE cases than their unsuccessful controls $(\mathrm{OR}=0.55)$. However, this finding was not statistically significant $(\mathrm{p}=0.19)$. Similarly, repair of varicocele was associated with higher odds of having successful micro TESE (OR=9.00), although the association was insignificant $(\mathrm{p}=0.07)$.

Conclusion: Varicocele and varicocele repair may not be significant associates of success in NOA patients undergoing micro TESE.
\end{abstract}

Keywords: varicocele, micro tese, non-obstructive azoosperm
Volume 4 Issue I - 2017

\author{
Sultan A Althakafi,' Osama M Mustafa, ${ }^{2}$ Raouf \\ M Seyam, ${ }^{3}$ Naif AI Hathal, ${ }^{3}$ Said Kattan ${ }^{3}$ \\ 'Urology Department, King Saudi Medical city, Saudi Arabia \\ ${ }^{2}$ College of medicine, Alfaisal University, Saudi Arabia \\ ${ }^{3}$ Urology Department, King Faisal Specialist Hospital \& research \\ center, Saudi Arabia
}

Correspondence: Said Kattan, Consultant Urologist/ Andrologist, Urology Department, King Faisal Specialist Hospital \& Research Center, P.O. Box 3354, Riyadh 1 I 2 I I, Saudi Arabia, Tel 966-555459553,Email sathagafi@hotmail.com

Received: October 28, 2016 | Published: January 26, 2017

\section{Introduction}

Despite the advances in the management options, ${ }^{1-3}$ no adequate sperm retrieval can be achieved in a considerable proportion of nonobstructive azoospermia (NOA) patients. ${ }^{4}$ Besides the technical improvements, optimization of the patient's clinical status is one possible means by which the outcomes of sperm retrieval procedures could be improved. For example, lifestyle changes and habitual modifications (e.g. smoking cessation) may enhance spermatogenesis prior to extraction. ${ }^{5}$ Hormonal optimization has also been attempted, although with varying success rates. ${ }^{6,7}$ One possible optimization intervention is varicocele repair. ${ }^{8}$ Varicocele is a relatively common pathology, ${ }^{9}$ found in around $5 \%-10 \%$ of azoospermia cases. ${ }^{10}$ Its negative effects on fertility has been recognized:11 a study of over 9000 men presenting to infertility clinics indicated a significant association between varicoceles and abnormal semen findings, testicular-volume parameters, as well as other parameters of testicular function. ${ }^{12}$ Others have suggested varicocele to be age-related with a progressively detrimental effect on fertility. ${ }^{13}$ Correcting varicocele may result in improved fertility. ${ }^{14,15}$ In 1952, Tulloch reported the first post-varicocele-repair spontaneous pregnancy, suggesting its potential positive effect on infertility outcomes..$^{16}$ A prospective randomized clinical trial of infertile men with palpable varicocele showed higher likelihood of semen-characteristics improvement and spontaneous pregnancy in repaired vs. conservatively-treated varicoceles. ${ }^{17}$

Despite these reports, the benefits of varicocele repair in NOA remains a debatable matter, ${ }^{18}$ as the current evidence also indicates the lack of any effect of varicocele repair on infertility. ${ }^{19,20}$ Of note, a recent systematic review identified relevant limitations of the overall evidence that would justify this procedure in sub fertile men. ${ }^{21}$ While microdissection testicular sperm extraction (micro TESE) offers the best chances of sperm retrieval in $\mathrm{NOA}^{2,3}$ the effect of varicocele and its repair on micro TESE outcomes is controversial. Of the few available reports, some suggested better outcomes when repaired, ${ }^{10,22}$ while others showed no added benefit. ${ }^{20}$ In this study, we attempt to investigate the association between varicocele (and varicocele repair) and the outcomes of micro TESE in NOA patients.

\section{Case presentation}

This is a retrospective, case-control study. The relevant data were collected through retrospective chart review of NOA patients treated under the care of the Urology Department of our tertiary referral center during the period Aug 2009-Aug 2015. Cases were defined as NOA patients who underwent micro TESE in whom the operation resulted in successful retrieval of at least one sperm. The controls were selected from the pool of NOA patients for whom micro TESE resulted in no sperm retrieval (i.e. micro TESE was unsuccessful) within the study period. Cases were matched with controls based on age, serum testosterone levels and histopathological diagnosis. One standard deviation was allowed as the matching criterion of tolerance for each of age $(6.85$ years $)$ and testosterone $(6.83 \mathrm{nmol} / \mathrm{L})$. Histological subtype was an exact match. The intended ratio of patients to controls was 1:2. Random selection of eligible controls was applied for each case, where possible.

Varicocele and its repair status served as the "exposure" variable in this study. The presence of varicocele was determined by ultrasonographic assessment of the spermatic veins and pampiniform plexus using the following criteria: dilated veins $>3 \mathrm{~mm}$ and/or the presence of reflux. ${ }^{23-25}$ Varicocele repair status was identified from the enrolled patients' records available at the hospital. Study findings were summarized using frequencies, means and standard deviations. Comparisons were made between the different populations using Student's t-, Chi-square and Fisher's exact tests, as appropriate. Odds ratios, along with their $95 \%$ confidence interval $(95 \% \mathrm{CI})$ were 
calculated for each of the explored relationships. All analyses were conducted using Statistical Package for Social Sciences (SPSS) v22.0. Armonk, NY: IBM Corp. A p $<0.05$ was considered significant.

\section{Ethical consideration}

The study was reviewed and approved by the Research Advisory Council (RAC), the institutional review board at our institution.

\section{Discussion}

A total of 32 cases and 56 controls were matched, and thus, included in the analysis. The mean age of the studied patients was 35.5 years, with a range of 24 to 53 . Overall, sertoli-cell only syndrome constituted the major histological pattern seen in dissected testes (77.3\%). Demographic, hormonal and ultrasonographic characteristics of, and micro TESE outcomes in, the study population are shown in Table 1. Table $2 \&$ Table 3 shows the distribution of varicocele and varicocele repair, respectively, among cases and controls. There was a $45 \%$ reduction in the odds of having ultrasonographic evidence of varicocele in successful micro TESE cases compared to unsuccessful controls $(\mathrm{OR}=0.547 ; 95 \% \mathrm{CI}=0.224-1.341)$. However, this decrease was insignificant $(\mathrm{p}=0.186)$. Likewise, varicocele repair was not significantly different between cases and controls in whom varicocele is present $(\mathrm{p}=0.066)$, despite being associated with 9 times higher odds of having successful than unsuccessful micro TESE outcomes $(\mathrm{OR}=9.000 ; 95 \% \mathrm{CI}=0.919-88.162)$.

Table I Sample characteristics and micro TESE outcomes

\begin{tabular}{|c|c|c|c|c|c|}
\hline \# & Variable & $\begin{array}{l}\text { Mean } \pm S D(n)-\text { Cases } \\
\text { Frequency }(\%)-\text { Cases }\end{array}$ & $\begin{array}{l}\text { Mean } \pm \text { SD }(n)-\text { Controls } \\
\text { Frequency }(\%) \text { - Controls }\end{array}$ & $\begin{array}{l}\text { Mean } \pm S D(n) \text { - overall } \\
\text { Frequency }(\%) \text { - overall }\end{array}$ & $\begin{array}{l}\text { P value } \\
\text { (Cases vs } \\
\text { Controls) }\end{array}$ \\
\hline I & Age & $36.28 \pm 6.73(32)$ & $35.09 \pm 6.21(56)$ & $35.52 \pm 6.39(88)$ & 0.403 \\
\hline 2 & BMI & $31.49 \pm 7.02(32)$ & $31.88 \pm 8.40(56)$ & $31.74 \pm 7.89(88)$ & 0.822 \\
\hline 3 & $\begin{array}{l}\text { Thyroid stimulating } \\
\text { hormone (TSH) }\end{array}$ & $2.62 \pm 2.04(3 \mathrm{I})$ & $2.44 \pm 1.67(5 \mathrm{I})$ & $2.5 I \pm I .8 I(82)$ & 0.654 \\
\hline 4 & $\begin{array}{l}\text { Follicular stimulating } \\
\text { hormone }(\mathrm{FSH})\end{array}$ & $17.08 \pm 10.57(32)$ & $21.82 \pm 18.4(56)$ & $20.10 \pm 16.10(88)$ & 0.128 \\
\hline 5 & $\begin{array}{l}\text { Luteinizing hormone } \\
\text { (LH) }\end{array}$ & $10.36 \pm 6.05$ & $12.28 \pm 8.56(56)$ & I I.58 $\pm 7.76(88)$ & 0.266 \\
\hline 6 & Prolactin & $11.15 \pm 6.84(32)$ & $10.52 \pm 4.29(55)$ & $10.75 \pm 5.34(87)$ & 0.603 \\
\hline 7 & Estradiol (E2) & $98.95 \pm 55.83(12)$ & $|26 \pm 78.9|$ (20) & $116.16 \pm 71.45(32)$ & 0.299 \\
\hline 8 & Testosterone & $11.16 \pm 5.44(32)$ & $10.8 \mid \pm 5.72(56)$ & $10.93 \pm 5.59(88)$ & 0.781 \\
\hline \multirow[t]{3}{*}{10} & US volume & $(n=32)$ & $(n=56)$ & $(n=88)$ & $>0.05$ \\
\hline & Normal & $23(71.9)$ & $4 \mid(73.2)$ & $64(72.7)$ & \\
\hline & Small & $9(28.1)$ & $15(26.8)$ & $24(27.3)$ & \\
\hline \multirow[t]{4}{*}{ II } & US varicocele present & $(n=32)$ & $(n=56)$ & $(n=87)$ & - \\
\hline & Right & $6(18.8)$ & $9(16.4)$ & $15(17.2)$ & \\
\hline & Left & $15(48.4)$ & $19(33.9)$ & $34(39.1)$ & \\
\hline & Right or left & $15(48.4)$ & $19(33.9)$ & $34(39.1)$ & \\
\hline \multirow[t]{3}{*}{12} & Varicocele Repair & $(n=32)$ & $(n=55)$ & $(n=88)$ & - \\
\hline & Yes & $5(15.6)$ & $\mathrm{I}(\mathrm{I} .8)$ & $6(6.8)$ & \\
\hline & No & $27(84.4)$ & $55(98.2)$ & $82(93.2)$ & \\
\hline \multirow[t]{3}{*}{13} & $\begin{array}{l}\text { Bone marrow } \\
\text { transplantation }\end{array}$ & $(n=32)$ & $(n=55)$ & $(n=87)$ & $>0.05$ \\
\hline & Yes & I (3.I) & $\mathrm{I}(\mathrm{I} .8)$ & $2(2.3)$ & \\
\hline & No & $31(96.9)$ & $54(96.4)$ & $85(96.6)$ & \\
\hline \multirow[t]{3}{*}{14} & Chromosomal analysis & $(n=5)$ & $(n=11)$ & $(n=16)$ & $>0.05$ \\
\hline & Normal & $4(80)$ & $8(72.7)$ & $12(75)$ & \\
\hline & XXY, 47 & I (20) & $3(27.3)$ & $4(25)$ & \\
\hline \multirow[t]{3}{*}{15} & $\begin{array}{l}\text { Pre-treatment with } \\
\text { clomiphene or B-HCG }\end{array}$ & $(n=32)$ & $(n=56)$ & $(n=88)$ & $>0.05$ \\
\hline & Yes & $2(6.25)$ & II (19.6) & $13(14.7)$ & \\
\hline & No & $30(93.75)$ & $45(80.4)$ & $75(85.3)$ & \\
\hline \multirow[t]{3}{*}{16} & Micro TESE Outcome & $(n=32)$ & $(n=56)$ & $(n=88)$ & N/A \\
\hline & Positive & $32(100)$ & $0(0)$ & $32(36.4)$ & \\
\hline & Negative & $0(0)$ & $56(100)$ & $56(63.6)$ & \\
\hline
\end{tabular}


Table Continues...

\begin{tabular}{|c|c|c|c|c|c|}
\hline \# & Variable & $\begin{array}{l}\text { Mean } \pm S D(n)-\text { Cases } \\
\text { Frequency (\%) -Cases }\end{array}$ & $\begin{array}{l}\text { Mean士SD (n) - Controls } \\
\text { Frequency (\%) - Controls }\end{array}$ & $\begin{array}{l}\text { Mean } \pm \text { SD }(n) \text { - overall } \\
\text { Frequency }(\%) \text { - overall }\end{array}$ & $\begin{array}{l}\text { P value } \\
\text { (Cases vs } \\
\text { Controls) }\end{array}$ \\
\hline \multirow[t]{5}{*}{17} & Histopathology & $(n=27)$ & $(n=48)$ & $(n=75)$ & $>0.05$ \\
\hline & Sertoli-cell syndrome & $20(74.1)$ & $38(79.2)$ & $58(77.3)$ & \\
\hline & Hypospermatogenesis & $5(18.5)$ & $6(10.7)$ & II (I4.7) & \\
\hline & $\begin{array}{l}\text { Maturation arrest- } \\
\text { early }\end{array}$ & $2(7.4)$ & $4(7.1)$ & $6(8)$ & \\
\hline & Maturation arrest-late & $0(0)$ & $0(0)$ & $0(0)$ & \\
\hline \multirow[t]{3}{*}{18} & Sperm motility & $(n=29)$ & $\mathrm{N} / \mathrm{A}$ & $\mathrm{N} / \mathrm{A}$ & $N / A$ \\
\hline & Motile & $10(34.5)$ & & & \\
\hline & Non-motile & $19(65.5)$ & & & \\
\hline 19 & $\begin{array}{l}\text { Number of straws } \\
\text { frozen }\end{array}$ & $3.22 \pm 2.24(32)$ & $N / A$ & $N / A$ & $N / A$ \\
\hline
\end{tabular}

Table 2 Varicocele distribution among successful-micro TESE cases and unsuccessful controls

\begin{tabular}{lll}
\hline & Varicocele & No varicocele \\
\hline Successful micro TESE & 15 & 16 \\
Unsuccessful micro TESE & 19 & 37
\end{tabular}

Table 3 Varicocele repair distribution among successful-micro TESE cases and unsuccessful controls with documented varicocele

\begin{tabular}{lll}
\hline & Repaired & Not repaired \\
\hline Successful micro TESE with varicocele & 5 & 10 \\
Unsuccessful micro TESE with varicocele & 1 & 18 \\
\hline
\end{tabular}

Varicocele may affect around $15 \%$ of the general population, ${ }^{26}$ $35 \%$ of primary infertility patients, ${ }^{27}$ and even a greater proportion of secondary infertility cases. ${ }^{28,29}$ It has received much attention because of the potential improvements of fertility outcomes after its repair. In fact, varicocele is believed to be among the most common correctable etiologies of infertility in men. ${ }^{9}$ Vascular perfusion appears to affect the quality of spermatogenesis. ${ }^{30}$ Indeed, several reports have shown associated derangements in semen parameters when varicocele is present, ${ }^{11,12}$ and shown improvements when varicocele is corrected. ${ }^{8,10,14,15,22,31,32}$ However, this association is not consistent. Several reports showed no benefit of varicocele repair on infertility ${ }^{19,33}$ and on micro TESE outcomes. ${ }^{20} \mathrm{~A}$ recent systematic review indicated evidence of fertility improvements after treatment of varicocele to be inadequate. ${ }^{21}$

In this paper, we found no difference between cases and controls in either varicocele or varicocele repair. Such findings may be an extension to the broader controversy concerning the effect of varicocele and varicocelectomy on fertility. It should be noted that the inconsistency may represent an otherwise multifaceted disease that needs a closer scrutinization; recent meta-analyses have suggested the repair's effect to be dependent on the underlying predominant histological pattern found on the testicular tissue biopsy. ${ }^{34,35}$ With having sperm in the ejaculate or spontaneous pregnancy as the successful outcome, Weedin et al. ${ }^{34}$ showed patients with hypospermatogenesis and late maturation arrest to have a significantly higher likelihood of success than those with sertoli-cell only or early maturation arrest histology. Similarly, Aboutaleb et al. ${ }^{36}$ showed the improvements in semen analysis parameters after varicocelectomy to be present in hypospermatogenesis histology but not in maturation arrest or sertoli- cell only pattern. To account for this observation, histological subtype was exactly matched between cases and each of their corresponding controls in this study. The majority of the cases showed sertoli-cell only histological pattern, which may have accounted for the lack of significant effect of varicocele repair on micro TESE outcomes that was observed in this study. ${ }^{36}$

Several limitations are to be acknowledged. First, the number of patients in both cases and controls arms is small. Second, "exposure" in this case-control design was defined by ultrasonographic criteria, which may differ in some cases from clinical counterpart; previous reports suggested doubtful benefit of subclinical-varicocele repair on fertility outcomes. ${ }^{33,37}$ Third, not many patients underwent varicocelectomy, and thus, it may limit the power of detection of the association between varicocele repairs with micro TESE outcomes. Finally, since this was a retrospective study, selection bias between cases and controls may exist. However, none of the clinical, radiological, or histopathological parameters were significantly different between the cases and control groups (Table 1). While this paper focused on NOA patients, the addition of a third "normal-fertility" control group, and investigating whether varicocele distribution is comparable to that of NOA patients may have provided insight into the varicocele's true effect on fertility in the studied population.

\section{Acknowledgments}

None.

\section{Conflicts of interest}

The author declares there is no conflict of interest.

\section{References}

1. Ramasamy R, Yagan N, Schlegel PN. Structural and functional changes to the testis after conventional versus microdissection testicular sperm extraction. Urology. 2005;65(6):1190-1194.

2. Deruyver Y, Vanderschueren D, Van der Aa F. Outcome of microdissection TESE compared with conventional TESE in non-obstructive azoospermia: a systematic review. Andrology. 2014;2(1):20-24.

3. Verza S, Esteves SC. Microsurgical versus conventional single-biopsy testicular sperm extraction in nonobstructive azoospermia: a prospective controlled study. Fertility and Sterility. 2011;96(3):S53.

4. Shin DH, Turek PJ. Sperm retrieval techniques. Nat Rev Urol. 2013;10(12):723-730. 
5. Janosek-Albright KJC, Schlegel PN, Dabaja AA. Testis sperm extraction. Asian Journal of Urology. 2015;2(2):79-84.

6. Hussein A, Ozgok Y, Ross L, et al. Optimization of spermatogenesisregulating hormones in patients with non-obstructive azoospermia and its impact on sperm retrieval: a multicentre study. BJU Int. 2013;111(3 Pt B):E110-E114.

7. Reifsnyder JE, Ramasamy R, Husseini J, et al. Role of optimizing testosterone before microdissection testicular sperm extraction in men with nonobstructive azoospermia. J Urol. 2012;188(2):532-536.

8. Cayan S, Kadioglu A, Orhan I, et al. The effect of microsurgical varicocelectomy on serum follicle stimulating hormone, testosterone and free testosterone levels in infertile men with varicocele. BJU Int. 1999;84(9):1046-1049.

9. Dubin L, Amelar RD. Etiologic factors in 1294 consecutive cases of male infertility. Fertil Steril. 1971;22(8):469-474.

10. Haydardedeoglu B, Turunc T, Kilicdag EB, et al. The effect of prior varicocelectomy in patients with nonobstructive azoospermia on intracytoplasmic sperm injection outcomes: a retrospective pilot study Urology. 2010;75(1):83-86.

11. Cozzolino DJ, Lipshultz LI. Varicocele as a progressive lesion: positive effect of varicocele repair. Hum Reprod Update. 2001;7(1):55-58.

12. World Health Organization. The influence of varicocele on parameter of fertility in a large group of men presenting to infertility clinics. World Health Organization. Fertil Steril. 1992;57(6):1289-1293.

13. Chehval MJ, Purcell MH. Deterioration of semen parameters over time in men with untreated varicocele: evidence of progressive testicular damage. Fertil Steril. 1992;57(1):174-177.

14. Matthews GJ, Matthews ED, Goldstein M. Induction of spermatogenesis and achievement of pregnancy after microsurgical varicocelectomy in men with azoospermia and severe oligoasthenospermia. Fertil Steril. 1998;70(1):71-75.

15. Zini A, Boman J, Jarvi K, et al. Varicocelectomy for infertile couples with advanced paternal age. Urology. 2008;72(1):109-113.

16. Tulloch W. Consideration of Sterility, sub fertility in male. Edinb Med J 1952;59:29-34.

17. Abdel-Meguid TA1, Al-Sayyad A, Tayib A, et al. Does varicocele repair improve male infertility? An evidence-based perspective from a randomized, controlled trial. Eur Urol. 2011;59(3):455-461.

18. Will MA, Swain J, Fode M, et al. The Great Debate: Varicocele Treatment and Impact on Fertility. Fertil Steril. 2011;95(3):841-852.

19. Nilsson S, Edvinsson A, Nilsson B. Improvement of semen and pregnancy rate after ligation and division of the internal spermatic vein: fact or fiction? Br J Urol. 1979;51(6):591-596.

20. Schlegel PN, Kaufmann. Role of varicocelectomy in men with nonobstructive azoospermia. Fertil Steril. 2004;81(6):1585-1588.

21. Kroese AC, de Lange NM, Collins J, et al. Surgery or embolization for varicoceles in subfertile men. Cochrane Database Syst Rev. 2012;10:Cd000479.

22. Inci K, Hascicek M, Kara O, et al. Sperm retrieval and intracytoplasmic sperm injection in men with nonobstructive azoospermia, and treated and untreated varicocele. J Urol. 2009;182(4):1500-1505.

23. Rifkin MD, Foy PM, Kurtz AB, et al. The role of diagnostic ultrasonography in varicocele evaluation. J Ultrasound Med. 1983;2(6):271-275.

24. McClure RD, Hricak H. Scrotal ultrasound in the infertile man: detection of subclinical unilateral and bilateral varicoceles. J Urol. 1986;135(4):711715 .

25. Wolverson MK, Houttuin E, Heiberg E, et al. High-resolution real-time sonography of scrotal varicocele. AJR Am J Roentgenol. 1983;141(4):775779

26. Belloli G, D’Agostino S, Pesce C, et al. Varicocele in childhood and adolescence and other testicular anomalies: an epidemiological study. Pediatr Med Chir. 1993;15(2):159-162.

27. Pryor J, Howards S. Varicocele. Urol Clin North Am. 1987;14:499-513.

28. Gorelick JI, Goldstein M. Loss of fertility in men with varicocele. Fertil Steril. 1993;59(3):613-616.

29. Witt MA, Lipshultz LI. Varicocele: a progressive or static lesion? Urology. 1993;42(5):541-543

30. Herwig R, Tosun K, Pinggera GM, et al. Tissue Perfusion Essential for Spermatogenesis and Outcome of Testicular Sperm Extraction (TESE) for Assisted Reproduction. J Assist Reprod Genet. 2004;21(5):175-180.

31. Marmar JL, Agarwal A, Prabakaran S, et al. Reassessing the value of varicocelectomy as a treatment for male subfertility with a new metaanalysis. Fertil Steril. 2007;88(3):639-648.

32. Mustafa Kir, Nuri Deniz, Hasan Biri. The effect of microsurgical varicocelectomy on semen parameters in men with non-obstructive azoospermia. Curr Urol. 2013;6(3):136-140.

33. Yamamoto M, Hibi H, Hirata Y, et al. Effect of varicocelectomy on sperm parameters and pregnancy rate in patients with subclinical varicocele: a randomized prospective controlled study. J Urol. 1996;155(5):1636-1638.

34. Weedin JW, Khera M, Lipshultz L. Varicocele repair in patients with nonobstructive azoospermia: a meta-analysis. J Urol. 2010;183(6):23092315 .

35. Elzanaty S. Varicocele repair in non-obstructive azoospermic men: diagnostic value of testicular biopsy - a meta-analysis. Scand $J$ Urol. 2014;48(6):494-498.

36. Aboutaleb HA, Elsherif EA, Omar MK, et al. Testicular Biopsy Histopathology as an Indicator of Successful Restoration of Spermatogenesis after Varicocelectomy in Non-obstructive Azoospermia. World J Mens Health. 2014;32(1):43-49.

37. Jarow JP, Ogle SR, Eskew LA. Seminal improvement following repair of ultrasound detected subclinical varicoceles. J Urol. 1996;155(4):12871290. 